\title{
Comparison of 6-minute walk test performance between male Active Duty soldiers and servicemembers with and without traumatic lower- limb loss
}

\author{
Alison A. Linberg, DPT, ATC; ${ }^{1}$ Kathryn E. Roach, PhD, PT; ${ }^{2}$ MAJ (Ret) Stuart M. Campbell, MPT; ${ }^{3}$ COL \\ (Ret) Paul D. Stoneman, PhD, MPT, DPT, OCS, SCS; ${ }^{4}$ Ignacio A. Gaunaurd, PhD, MSPT; ${ }^{5}$ Michele A. Raya, \\ PhD, PT, SCS, ATC; ${ }^{2}$ Carlos Gomez-Orozco; ${ }^{5}$ Robert S. Gailey, PhD, PT ${ }^{2,5 *}$ \\ ${ }^{1}$ Military Advanced Training Center, Walter Reed Army Medical Center, Washington, DC; ${ }^{2}$ Department of Physical \\ Therapy, Miller School of Medicine, University of Miami, Coral Gables, FL; ${ }^{3}$ Center for the Intrepid, Brooke Army Med- \\ ical Center, San Antonio, TX; ${ }^{4}$ Physical Therapy, Walter Reed Army Medical Center, Washington, DC; ${ }^{5}$ Miami Depart- \\ ment of Veterans Affairs Healthcare System, Miami, FL
}

\begin{abstract}
The rehabilitation of U.S. military servicemembers (SMs) who have sustained a traumatic loss of one or both lower limbs requires outcome measures that can assess their physical capabilities in comparison with their uninjured colleagues. Describing reference ranges for the 6-minute walk test (6MWT) in both populations will help clinicians develop appropriate goals for rehabilitation and document progress toward those goals. A convenience sample of 118 male U.S. SMs with and 97 without traumatic lower-limb loss participated in this study. All participants completed a 6MWT, and comparisons were made between SMs with and without limb loss and among the levels of limb loss. The SMs without lower-limb loss performed significantly better than all SMs with lower-limb loss. The SMs with transtibial limb loss performed significantly better than those with all other levels of limb loss. Statistically significant and clinically relevant differences were also noted between the other levels of limb loss. No differences were found between different prosthetic components. Reference ranges were established for U.S. SMs with and without various levels of limb loss, and the 6MWT was able to identify functional differences between groups.
\end{abstract}

Key words: 6-minute walk test, amputation, amputee, endurance measure, functional testing, limb loss, performance measure, rehabilitation, U.S. servicemembers, walk test.

\section{INTRODUCTION}

An estimated 1.5 million men and women currently serve as Active Duty servicemembers (SMs) in the U.S. military, the majority of whom are under the age of 25 [1]. At the time of the study, there were close to 200,000 SMs deployed to Iraq or Afghanistan [2], and these conflicts have added to the growing number of individuals with traumatic lower-limb loss. Returning wounded SMs with lower-limb loss often have the ability to return to

Abbreviations: $6 \mathrm{MWT}=6$-minute walk test, $\mathrm{ANOVA}=$ analysis of variance, ATS = American Thoracic Society, BAMC = Brooke Army Medical Center, BTFA = bilateral transfemoral amputation, $\mathrm{BTTA}=$ bilateral transtibial amputation, IRB = institutional review board, NNMCSD $=$ National Naval Medical Center San Diego, SM = servicemember, TFA = unilateral transfemoral amputation, TTA = unilateral transtibial amputation, WRAMC $=$ Walter Reed Army Medical Center.

*Address all correspondence to Robert S. Gailey, PhD, PT; Department of Physical Therapy, Miller School of Medicine, University of Miami 5915 Ponce de Leon Blvd, Plummer Building 5th floor, Coral Gables, FL 33146; 305-2844535; fax: 305-284-6128. Email: rgailey@miami.edu http://dx.doi.org/10.1682/JRRD.2012.05.0098 
high levels of mobility and physical activity, including returning to Active Duty in combat roles. From the onset of Operation Iraqi Freedom and Operation Enduring Freedom to September 1, 2010, 1,033 SMs have sustained a major limb loss [3].

The U.S. Armed Forces is a unique cohort of individuals with distinctive demographic characteristics and occupational physical requirements. All branches of the military include physical fitness as an essential component of most SMs' job requirements and make it an objective of military physical fitness programs. Fitness is also a goal of military rehabilitation programs, necessitating the use of appropriate performance measures to assess readiness for duty or return to premorbid fitness level after injury. The need to assess fitness, mobility, and function in people with lower-limb loss has required the use of a number of different outcome measures in this population. These measures include many that are typically used in the elderly civilian population with and without limb loss, including the Timed Up and Go, Ltest, 2-minute walk test, 6-minute walk test (6MWT), and Amputee Mobility Predictor [4-17]. Many of these measures have also been assessed in a relatively healthy younger population with or without lower-limb loss.

During his $13 \mathrm{yr}$ in the U.S. Army and Air Force, COL Kenneth Cooper, MD, was the first to introduce the concept of timed run tests for healthy individuals with the 12-minute physical fitness test [18]. The 12-minute physical fitness test was modified to a 12-minute walk test for people with bronchitis [19]. It was soon replaced by the $6 \mathrm{MWT}$ when it was determined to perform just as well as the 12-minute version in people with respiratory disease [20]. A review of functional walking tests in people with cardiorespiratory disease concluded that "the 6MWT is easy to administer, better tolerated, and more reflective of activities of daily living than other walk tests" [21, p. 256]. The 6MWT is considered a submaximal test of functional capacity, because most people do not achieve maximal capacity during testing [22]. In the healthy population, the 6MWT has been identified as a performancebased outcome measure that assesses mobility, aerobic capacity, and physical function. In healthy individuals older than $20 \mathrm{yr}$, age, height, and sex have been found to be good predictors of 6MWT performance [23-24].

The 6MWT has also been used as a measure of functional mobility in various clinical populations, including stroke [25], traumatic brain injury [26], and mobility impairment [27]. In people with lower-limb amputation, the 6MWT was found to be reliable, valid, and able to differentiate among functional levels [8]. A minimal detectable change distance of $45 \mathrm{~m}$ has been identified in unilateral transtibial amputees and transfemoral amputees [16]. The 6MWT has been used to identify the contribution of prosthetic feet to distance walked and walking speed. Differences in walking distance with younger amputees have been reported between nondynamic prosthetic feet and dynamic response storage and return feet and the contribution of prosthetic feet to distance walked in 6 min can be between 5 to 15 percent depending on level of limb loss and functional level [28]. The influence of the prosthetic foot on walking velocity appears to be a product of the J-shaped carbon fiber design, which permits greater dorsiflexion and balance over the full-length footplate, thus increasing the rate of progression of the center of pressure from rearfoot to forefoot [29-31]. To date, no differences within the carbon-fiber energy storage and return feet designs have been reported. Prosthetic knees have not been found to influence walking speed.

Although running tests are often used as a fitness measure in uninjured SMs, the 6MWT has a number of advantages in the military rehabilitation setting, where many patients do not have the physical capacity to run because of cardiorespiratory impairments, healing tissues, risk of injury and, in most facilities, space limitations. The purpose of this study was to describe 6MWT performance in young healthy male SMs with and without limb loss. This study examined differences in 6MWT performance among SMs without limb loss and with different levels of limb loss. We hypothesized that 6MWT performance would differentiate between subjects with and without limb loss and between levels of limb loss, with lower performances by SMs with more proximal amputation. The study also examined the relationship between 6MWT and demographic and clinical characteristics and tested whether the type of prosthetic foot and knee components influenced 6MWT performance.

\section{METHODS}

\section{Study Participants}

A convenience sample of 215 male Active Duty and retired SMs with and without traumatic lower-limb loss was recruited to participate in this study. All participants were between the ages of 18 and 40, in general good 
health, and without injury or medical condition that would preclude exercise. Females were not included because they account for 2-3 percent of the current population of SMs with limb loss [32-33]. The participants with lower-limb loss were medically stable, had a properly fitting prosthesis, and demonstrated a minimal level of function as determined by the Amputee Mobility Predictor [8] (37 points) and/or 6MWT (250 m). Participants were excluded if they had spinal cord injury; upper-limb loss; peripheral nerve injury that limited function; inability to follow commands because of traumatic brain injury; or orthopedic, cardiopulmonary, or contralateral limb injuries that limited mobility or that contraindicated exercise.

Participants without limb loss were recruited from Fort Bragg, North Carolina, and those with limb loss were recruited through the Armed Forces Amputee Patient Care Program, which includes the programs at Walter Reed Army Medical Center (WRAMC) in Washington, DC; Brooke Army Medical Center (BAMC) in San Antonio, Texas; and National Naval Medical Center San Diego (NNMCSD) in San Diego, California. All testing occurred at Fort Bragg, WRAMC, and BAMC.

\section{Testing Procedure}

Demographic and anthropometric data, including age, height, weight, waist circumference, and time since amputation, were collected for each participant. The prosthetic components each participant wore for testing were also noted.

Administration of the 6MWT was largely consistent with recommendations by the American Thoracic Society (ATS) [22]. The participants completed the 6MWT after completing other agility measures, so the participants were reminded that the 6MWT was "not a cool down" and were given standardized instructions consistent with the ATS guidelines that encouraged the participant "to cover as much distance as possible" and included a demonstration of the task. Participants were provided a 10 min rest before initiation of the $6 \mathrm{MWT}$, so fatigue from the previous testing was not a concern.

The ATS guidelines for the 6MWT were written specifically for subjects with cardiopulmonary rather than neuromusculoskeletal impairments [22]. The ATS standard $30 \mathrm{~m}$ straight course has often been modified when the 6MWT is performed with clinical populations [2527]. Out of concern for the safety of individuals with bilateral lower-limb loss, we modified the shape of the testing course from a straight course to a rectangular course $28.95 \mathrm{~m}(95 \mathrm{ft})$ or $30.48 \mathrm{~m}(100 \mathrm{ft})$ in length and

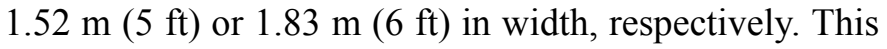
course configuration eliminated the need to perform a pivot turn and allowed participants to circle the course without interruption of cadence. This modification is similar to that utilized by Mossberg and Fortini in their study of the 6MWT in individuals with traumatic brain injury [26]. All the tracks were rectangular in shape; however, the track lengths ranged from $61 \mathrm{~m}(200 \mathrm{ft})$ to $65 \mathrm{~m}(212 \mathrm{ft})$ across the testing sites. Previous research found that differences in the track length did not affect 6MWT performance; however, continuous tracks produced better 6MWT performance than straight line tracks [34]. We recognize that the rectangular course configuration may have increased the distance walked; however, all participants were tested using the same course configuration so that comparisons among the groups tested remained internally valid. The participants were instructed to walk the 6MWT course, maintaining one foot in contact with the ground at all times, covering as much distance as possible in the $6 \mathrm{~min}$. On completion of the 6MWT, the distance walked was measured and recorded in meters to determine 6MWT performance.

\section{Statistical Analysis}

Statistical analysis was performed using SAS version 9.1.3 (SAS Institute Inc; Cary, North Carolina). Descriptive statistics were calculated to characterize the participants by group. Demographic and 6MWT data were compared among SMs without limb loss and SMs with each level of limb loss. All groups met the assumptions of normality for the 6MWT, so comparisons were analyzed using a one-way analysis of variance (ANOVA), followed by post hoc Tukey honestly significant difference analysis if significant differences existed. Because age and height were not normally distributed, Spearman correlation coefficients were calculated to examine the relationship between demographic and clinical factors and the 6MWT performance for participants without limb loss and for those with unilateral transtibial amputation (TTA) and unilateral transfemoral amputation (TFA). Within the TTA and TFA groups, participants using different prosthetic feet and prosthetic knees, respectively, were compared using ANOVAs and Student $t$-tests. Level of significance was set at $p \leq 0.05$. Because of the small number of SMs in each bilateral category, participants with bilateral lower-limb loss were not included in the last two analyses. 


\section{RESULTS}

A total of 215 male Active Duty and veteran U.S. SMs, 118 with a traumatic lower-limb loss and 97 without, completed this study. Select demographic, clinical, and anthropometrics characteristics are summarized in Table 1. The participants with lower-limb loss had different levels of amputation: 60 TTA, 32 TFA, 12 bilateral transtibial amputation (BTTA), 7 bilateral transfemoral amputation (BTFA), and 7 combination lower-limb amputees with a transtibial and transfemoral amputation. At the time of testing, they all had completed skilled rehabilitation and were either awaiting disposition $(n=$ $42,36 \%)$, had returned to Active Duty $(n=32,27 \%)$, or retired from the Armed Forces $(n=44,37 \%)$. Those SMs with knee disarticulation amputation were placed in the TFA group. Although the groups appeared similar in most characteristics, there were some differences between those without limb loss and those with limb loss. (Table 1)

Statistically significant differences $(F=53.04, p<$ 0.001 ) in mean 6MWT performance were noted among the groups with and without limb loss (Table 2). Post hoc testing demonstrated significant difference in mean performances in 6MWT between the group without limb loss and the TTA group $(p<0.001)$, and both the participants without limb loss and the TTA participants were significantly different from all other groups $(p \leq 0.03)$. There was also a significant difference in 6MWT performance between BTTA and BTFA participants $(p=0.03)$.
Although differences existed in group mean distance, there was substantial overlap among all groups in the range of 6MWT performance.

In participants with TTA and TFA, weak to moderate negative correlations were found between both weight and waist size and 6MWT (Table 3). Individuals who weighed more or had larger waist sizes walked shorter distances. There was a moderate positive relationship between height and 6MWT performance in those with TTA but not in those with TFA. There were weak correlations between 6MWT performance and age and height for participants without limb loss.

Prosthetic feet were classified as carbon fiber Jshaped energy storage and return feet with shock absorbers and/or torque rotators [1]; carbon fiber J-shaped energy storage and return feet without shock absorbers or torque rotators [2]; and low-profile energy storage and return feet without carbon fiber J-shaped pylon, shock absorbers, or torque rotators prosthetic feet [3]. Prosthetic knee units were classified as microprocessor [1] or nonmicroprocessor [2]. No statistically significant differences in 6MWT performance were noted between prosthetic feet $(p=0.26)$ and prosthetic knees $(p=0.87)$, within groups (Figure).

\section{DISCUSSION}

This study is the first to report 6MWT performance for young, healthy males with limb loss who have

Table 1.

Descriptive statistics (mean \pm standard deviation) of participating servicemembers (SMs) with and without lower-limb loss.

\begin{tabular}{|c|c|c|c|c|c|c|}
\hline \multirow{2}{*}{ Characteristic } & \multirow{2}{*}{$\begin{array}{c}\text { Without Limb } \\
\text { Loss }\end{array}$} & \multicolumn{5}{|c|}{ With Limb Loss } \\
\hline & & TTA & TFA & BTTA & BTFA & TTA/TFA \\
\hline$n$ & 97 & 60 & 32 & 12 & 7 & 7 \\
\hline $\operatorname{Age}(y r)^{*}$ & $26.1 \pm 5.5$ & $28.5 \pm 5.8$ & $30.6 \pm 5.5$ & $29.7 \pm 5.8$ & $26.6 \pm 2.8$ & $28.7 \pm 7.1$ \\
\hline Weight $(\mathrm{kg})^{\dagger}$ & $82.0 \pm 10.2$ & $90.1 \pm 16.1$ & $91.3 \pm 12.2$ & $97.8 \pm 20.3$ & $75.1 \pm 9.8$ & $95.1 \pm 13.4$ \\
\hline Waist $(\mathrm{cm})^{\ddagger \S}$ & $86.1 \pm 6.9$ & $92.5 \pm 10.2$ & $95.5 \pm 8.9$ & $99.3 \pm 9.1$ & $87.4 \pm 6.9$ & $101.3 \pm 10.4$ \\
\hline $\begin{array}{l}{ }^{*} \text { Significant difference betwee } \\
{ }^{\dagger} \text { Significant difference }(p<0.0 \\
\text { tSignificant difference }(p<0.0 \\
{ }^{\$} \text { Significant difference }(p<0.0 \\
\text { BTFA = bilateral transfemoral }\end{array}$ & $\begin{array}{l}\text { SMs with TFA and } \\
\text { 5) between SMs wit } \\
\text { 5) between SMs wit } \\
01 \text { ) between SMs w } \\
\text { amputation, BTTA = }\end{array}$ & $\begin{array}{l}\text { ut limb loss }(p= \\
\text { A and all levels } \\
\text { A and BTTA and } \\
\text { imb loss and wi } \\
\text { ral transtibial an }\end{array}$ & $\begin{array}{l}\text {. } \\
\text { A and TTA/TFA. } \\
\text { b loss except for } \\
\text { ion, NA = not ap }\end{array}$ & $\begin{array}{l}\text { e with BTFA } \\
\text { ble, TFA = un }\end{array}$ & 99). & on, $\mathrm{TTA}=\mathrm{u}$ \\
\hline
\end{tabular}


Table 2.

Comparison of 6-minute walk test (6MWT) distance between participating servicemembers (SMs) with and without lower-limb loss.

\begin{tabular}{|c|c|c|c|c|c|c|}
\hline \multirow{2}{*}{ 6MWT (m) } & \multirow{2}{*}{$\begin{array}{c}\text { Without Limb } \\
\text { Loss }\end{array}$} & \multicolumn{5}{|c|}{ With Limb Loss } \\
\hline & & TTA & TFA & BTTA & BTFA & TTA/TFA \\
\hline$n$ & 97 & 60 & 32 & 12 & 7 & 7 \\
\hline Mean $\pm \mathrm{SD}^{* \dagger}$ & $761 \pm 87$ & $661 \pm 87$ & $542 \pm 67$ & $576 \pm 75$ & $452 \pm 141$ & $503 \pm 89$ \\
\hline 25th Percentile & 703 & 626 & 490 & 520 & 313 & 485 \\
\hline 50th Percentile & 765 & 664 & 533 & 559 & 443 & 520 \\
\hline
\end{tabular}

*Significant differences between SMs without limb loss and with TTA vs other groups $(p<0.001)$.

†Significant difference between SMs with BTTA and BTFA $(p=0.03)$.

$\mathrm{BTFA}=$ bilateral transfemoral amputation, $\mathrm{BTTA}=$ bilateral transtibial amputation, $\mathrm{SD}=$ standard deviation, $\mathrm{TFA}=$ unilateral transfemoral amputation, $\mathrm{TTA}=$ unilateral transtibial amputation, TTA/TFA $=$ combination transtibial and transfemoral amputation.

Table 3.

Factors correlated with 6-minute walk distance for servicemembers with unilateral transtibial amputation (TTA) and unilateral transfemoral amputation (TFA): Spearman correlation $(r)$ with $p$-value given in parentheses.

\begin{tabular}{lcrr}
\hline \multicolumn{1}{c}{ Characteristic } & Without Limb Loss & With Limb Loss & TFA \\
\cline { 3 - 4 } Age $(\mathrm{yr})$ & 97 & 60 & 32 \\
Height $(\mathrm{cm})$ & $0.25(0.01)$ & $0.05(0.71)$ & $0.11(0.55)$ \\
Weight $(\mathrm{kg})$ & $0.21(0.04)$ & $0.40(0.002)$ & $-0.29(0.11)$ \\
Waist $(\mathrm{cm})$ & $0.15(0.14)$ & $-0.24(0.07)$ & $-0.46(0.008)$ \\
Time Since Amputation $(\mathrm{yr})$ & $0.08(0.44)$ & $-0.28(0.03)$ & $-0.35(0.05)$ \\
NA = not applicable. & NA & $0.21(0.11)$ & $0.05(0.77)$ \\
\hline
\end{tabular}

completed skilled rehabilitation. Other studies have reported 6MWT performance values in healthy adults and lower-limb amputees; none were conducted using participants drawn from a military population. However, the 6MWT values for participants in the second and third decade of life were similar to our results for the participants without limb loss [23]. The information on 6MWT performance for SMs with limb loss will allow clinicians to set goals that are appropriate for individual patients based on clinical presentation. Although this study found difference between SMs with and without lower-limb loss, it also found that almost 75 percent of the TTA and BTTA participants walked above the minimum distance recorded by those SMs without limb loss. Confirmation that physical performance after injury can be regarded within "normal" standards can be both gratifying and reassuring.

SMs with TTA had better 6MWT values than all other amputation level groups, and the mean 6MWT performance for those with BTTA was significantly greater than for those with TFA. These findings support the importance of preserving the knee joint when possible.

Many factors have been identified that affect 6MWT performance, including age, height, and weight. Height influences performance since taller individuals typically have a longer stride length [23-24,35]. Body weight has been identified as a predictor of 6MWT performance in middle-aged healthy adults, with heavier individuals not performing as well as light individuals, because differences in weight are often tied to difference in fitness [35]. Because the SMs without limb loss were relatively fit and fairly homogeneous in age, height, and weight, we found very weak correlations between demographic factors and 6MWT distance in this group.

Participants were instructed to wear the prosthesis that they felt most comfortable and confident in to perform the test. Differences in 6MWT performance were not found between the different types of prosthetic feet and knee units for those participants with TTA and TFA, respectively. Similar results recently reported that differences in 6MWT performance were not found between 
JRRD, Volume 50, Number 7, 2013

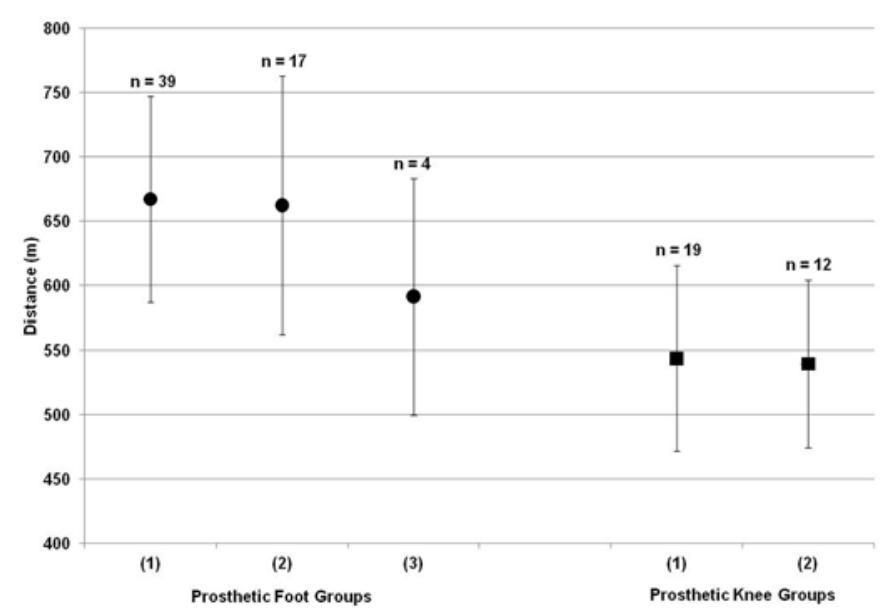

Figure.

Six-minute walk test performance (mean \pm standard deviation) of participants with unilateral transtibial $(n=60)$ and unilateral transfemoral $(n=32)$ limb loss walking with different prosthetic feet and knees. Prosthetic feet classifications (•): (1) carbon fiber J-shaped energy storing and return feet with shock absorbers and/or torque rotators, (2) carbon fiber J-shaped energy storing and return feet without shock absorbers or torque rotators, and (3) low-profile energy storing and return feet. Prosthetic knee unit classifications (ם): (1) microprocessor and (2) nonmicroprocessor.

different categories of prosthetic feet after specialized prosthetic training was administered to people with TTA [36]. The study results suggested that if a person has reached his or her optimal walking speed, performance related to prosthetic components may not significantly increase because he or she has reached maximal walking performance. For this population of young, fit SMs who completed skilled rehabilitation and were functioning at a high level, the 6MWT appeared to not be appropriate for detecting differences between specific prosthetic foot and knee components.

As are all performance-based tests, the 6MWT distance is affected by participant motivation. While all participants received the same standardized instructions, instructing them to "cover as much distance as possible," it was observed that not all participants appeared to be exerting a "maximum" effort. Once testing began, verbal cueing or encouragement was strictly prohibited. It is therefore possible that individual motivation during the $6 \mathrm{MWT}$ could have influenced the variability in 6MWT performance.
Our ability to detect differences among the bilateral limb-loss groups was limited by the relatively small sample sizes in these groups. However, our samples were larger than those reported in most publications. Finally, our participants may not be entirely representative of the general younger male population and/or individuals with traumatic lower-limb loss. All the participants without limb loss were volunteers and were, by virtue of being SMs, a physically fit group.

By establishing reference ranges for the 6MWT in a military population, the findings of this study will provide clinicians with the ability to set goals and gauge progress using measures relevant to the SMs under their care. Rehabilitative goals must be consistent with the patient's personal goals, and if the return to gainful employment within the military is still an aspiration, then parallel objective measures need to be identified. Running a predetermined distance is the measure of choice for aerobic capacity by the Army and Marine Corp. Although most SMs with limb loss will learn to run sometime during their rehabilitation process, doing so early in their rehabilitation may be ill-advised because of numerous other medical contraindications. However, the ability to walk is one of the primary functional tasks taught early in rehabilitation and is the focus of many hours of therapy. The 6MWT is a practical, safe test of functional mobility requiring very little equipment and is appropriate for use even in individuals with severe impairments early in rehabilitation.

Future work can identify specific treatment exercises and programs designed to improve walking performance. Threshold 6MWT performance by level of limb loss can be established to determine when running and higherlevel mobility skills can be introduced into the rehabilitation program. In addition, mean values for female SMs and individuals with limb loss with complex traumatic injuries should be established. Finally, the dedication of injured SMs to remain at a high level of activity and the state-of-the-art rehabilitation received by the wounded SMs likely account for their 6MWT performance and should be investigated to determine the contribution of skilled rehabilitation with respect to aerobic capacity and walking.

\section{CONCLUSIONS}

6MWT reference ranges were established for U.S. SMs without lower-limb loss and U.S. SMs with limb loss 
who completed skilled rehabilitation. The 6MWT distance of SMs without limb loss differed from those with lowerlimb loss, but there were substantial areas of distance overlap among all groups. Characteristics such as age, height, weight, and waist circumference moderately affected 6MWT. The 6MWT did not detect differences between the various prosthetic foot and knee units used by the SMs with limb loss. The 6MWT reference ranges established through this study will help clinicians and future young, active military and nonmilitary individuals with limb loss track progression of rehabilitation and set realistic goals to reach their full functional potential.

\section{ACKNOWLEDGMENTS}

\section{Author Contributions:}

Study concept and design: A. A. Linberg, K. E. Roach, R. S. Gailey, I. A. Gaunaurd.

Acquisition of data: M. A. Raya, R. S. Gailey, P. D. Stoneman, S. M. Campbell, C. Gomez-Orozco.

Analysis and interpretation of data: A. A. Linberg, K. E. Roach, R. S. Gailey, I. A. Gaunaurd.

Drafting of manuscript: A. A. Linberg, K. E. Roach, R. S. Gailey, I. A. Gaunaurd.

Critical revision of manuscript of important intellectual content:

A. A. Linberg, K. E. Roach, R. S. Gailey, M. A. Raya, I. A. Gaunaurd. Statistical analysis: K. E. Roach.

Study supervision: R. S. Gailey, I. A. Gaunaurd, S. M. Campbell.

Financial Disclosures: The authors have declared that no competing interests exist.

Funding/Support: This material was based on work supported by the Military Amputee Research Program and the Telemedicine and Advanced Technology Research Center (Prime Award No.

W81XWH-06-2-0073). The U.S. Army Medical Research Acquisition Activity, Fort Detrick, Maryland, is the awarding and administering acquisition office. It was administered by the Henry M. Jackson Foundation for the Advancement of Military Medicine, Inc, and the South Florida Veterans Affairs Foundation for Research and Education, Inc.

Additional Contributions: The authors would like to thank LTC Daniel Jayne, MPT, OCS; COL (Ret) Rebecca Hooper, PhD, PT; SGM (Ret) Brad Halling, CP; Orlando Gomez-Marin, MSc, PhD; Justin Z. Laferrier, MSPT, OCS, SCS, ATP, CSCS; John R. Fergason, CPO; Peter D. Harsch, CP; CAPT (Ret) Kathy Goldberg, MSPT; Nico Marcolongo; Jen Berrios, DPT; Erica Gagne, DPT; Carolyn Lindsay, DPT; and Adam Stivala, DPT, for their dedication and countless hours of work contributed to make this project a success. The authors also thank the staff at the Frederick Physical Fitness Center and Womack Army Medical Center at Fort Bragg, North Carolina; Center for the Intrepid, BAMC; Military Advanced Training Center, WRAMC; Amputee Care, Prosthetics, and Rehabilitation Department, NNMCSD; Research Department, Miami Department of Veterans Affairs Healthcare System; South Florida Veterans Affairs Foundation for Research and Education; and Challenged Athletes Foundation
Operation Rebound for their generous support of this project. Ms. Linberg is now with the Department of Defense-Department of Veterans Affairs Extremity Trauma and Amputation Center of Excellence, Department of Rehabilitation, Walter Reed National Military Medical Center, Bethesda, Maryland; MAJ (Ret) Campbell is now with the San Antonio Military Medical Center, Fort Sam Houston, Texas; and Dr. Stoneman is now with the Department of Physical Therapy, Rocky Mountain University of Health Professions, Provo, Utah.

Institutional Review: Approved by the institutional review board (IRB) at Womack Army Medical Center, WRAMC Department of Clinical Investigation, WRAMC Human Use Committee, BAMC Department of Clinical Investigation, BAMC Human Use Committee, Army Clinical Investigation Regulatory Office, and Human Studies Subcommittee at the Miami Department of Veterans Affairs Healthcare System. A research investigator reviewed and explained to each participant the eligibility criteria, methodology, confidentiality, and potential risks involved in study participation. Participant questions were asked before signing IRB-approved informed consent and protected health information form.

Participant Follow-Up: The authors plan to inform participants of the publication of this study.

Disclaimer: The views expressed in this article are those of the authors and do not reflect the official policy or position of the Department of the Army, Department of the Navy, Department of Defense, or U.S. Government, and no official endorsement should be inferred.

\section{REFERENCES}

1. Segal DR, Segal MW. America's military population. Popul Bull. 2004;59(4):23-24.

2. Belasco A. The cost of Iraq, Afghanistan, and other Global War on Terror operations since 9/11. Washington (DC): Congressional Research Service; 2011. p. 1-59.

3. Fischer H. U.S. military casualty statistics: Operation New Dawn, Operation Iraqi Freedom, and Operation Enduring Freedom. Washington (DC): Congressional Research Service; 2010.

4. Brooks D, Hunter JP, Parsons J, Livsey E, Quirt J, Devlin M. Reliability of the two-minute walk test in individuals with transtibial amputation. Arch Phys Med Rehabil. 2002;83(11):1562-65. [PMID:12422326]

http://dx.doi.org/10.1053/apmr.2002.34600

5. Brooks D, Parsons J, Hunter JP, Devlin M, Walker J. The 2minute walk test as a measure of functional improvement in persons with lower limb amputation. Arch Phys Med Rehabil. 2001;82(10):1478-83. [PMID:11588757] http://dx.doi.org/10.1053/apmr.2001.25153

6. Deathe AB, Miller WC. The L test of functional mobility: measurement properties of a modified version of the timed "up \& go" test designed for people with lower-limb amputations. Phys Ther. 2005;85(7):626-35. [PMID:15982169]

7. Frlan-Vrgoc L, Vrbanić TS, Kraguljac D, Kovacević M. Functional outcome assessment of lower limb amputees 
and prosthetic users with a 2-minute walk test. Coll Antropol. 2011;35(4):1215-18. [PMID:22397262]

8. Gailey RS, Roach KE, Applegate EB, Cho B, Cunniffe B, Licht S, Maguire M, Nash MS. The amputee mobility predictor: an instrument to assess determinants of the lowerlimb amputee's ability to ambulate. Arch Phys Med Rehabil. 2002;83(5):613-27. [PMID:11994800]

9. Gremeaux V, Damak S, Troisgros O, Feki A, Laroche D, Perennou D, Benaim C, Casillas JM. Selecting a test for the clinical assessment of balance and walking capacity at the definitive fitting state after unilateral amputation: a comparative study. Prosthet Orthot Int. 2012;36(4):415-22. [PMID:22389424] http://dx.doi.org/10.1177/0309364612437904

10. Hafner BJ, Willingham LL, Buell NC, Allyn KJ, Smith DG. Evaluation of function, performance, and preference as transfemoral amputees transition from mechanical to microprocessor control of the prosthetic knee. Arch Phys Med Rehabil. 2007;88(2):207-17. [PMID:17270519] http://dx.doi.org/10.1016/j.apmr.2006.10.030

11. Lin SJ, Bose NH. Six-minute walk test in persons with transtibial amputation. Arch Phys Med Rehabil. 2008;89(12): 2354-59. [PMID:18976979] http://dx.doi.org/10.1016/j.apmr.2008.05.021

12. Lythgo N, Marmaras B, Connor H. Physical function, gait, and dynamic balance of transfemoral amputees using two mechanical passive prosthetic knee devices. Arch Phys Med Rehabil. 2010;91(10):1565-70. [PMID:20875515] http://dx.doi.org/10.1016/j.apmr.2010.07.014

13. Matjacić Z, Burger H. Dynamic balance training during standing in people with trans-tibial amputation: a pilot study. Prosthet Orthot Int. 2003;27(3):214-20.

14. Parker K, Kirby RL, Adderson J, Thompson K. Ambulation of people with lower-limb amputations: relationship between capacity and performance measures. Arch Phys Med Rehabil. 2010;91(4):543-49. [PMID:20382285] http://dx.doi.org/10.1016/j.apmr.2009.12.009

15. Raya MA, Gailey RS, Fiebert IM, Roach KE. Impairment variables predicting activity limitation in individuals with lower limb amputation. Prosthet Orthot Int. 2010;34(1):73-84. [PMID:20196689] http://dx.doi.org/10.3109/03093640903585008

16. Resnik L, Borgia M. Reliability of outcome measures for people with lower-limb amputations: distinguishing true change from statistical error. Phys Ther. 2011;91(4):555-65. [PMID:21310896] http://dx.doi.org/10.2522/ptj.20100287

17. Schoppen T, Boonstra A, Groothoff JW, de Vries J, Göeken LN, Eisma WH. The Timed "up and go" test: reliability and validity in persons with unilateral lower limb amputation. Arch Phys Med Rehabil. 1999;80(7):825-28.

\section{[PMID:10414769]}

http://dx.doi.org/10.1016/S0003-9993(99)90234-4

18. Cooper KH. A means of assessing maximal oxygen intake. Correlation between field and treadmill testing. JAMA. 1968;203(3):201-4. [PMID:5694044] http://dx.doi.org/10.1001/jama.1968.03140030033008

19. McGavin CR, Gupta SP, McHardy GJ. Twelve-minute walking test for assessing disability in chronic bronchitis. BMJ. 1976;1(6013):822-23. [PMID:1260350]

http://dx.doi.org/10.1136/bmj.1.6013.822

20. Butland R, Pang J, Gross E, Woodcock A, Geddes D. Two, six, and 12-minute walking test in respiratory disease British J Med. 1984;284:1607-8.

21. Solway S, Brooks D, Lacasse Y, Thomas S. A qualitative systematic overview of the measurement properties of functional walk tests used in the cardiorespiratory domain. Chest. 2001;119(1):256-70. [PMID:11157613] http://dx.doi.org/10.1378/chest.119.1.256

22. ATS Committee on Proficiency Standards for Clinical Pulmonary Function Laboratories. ATS statement: guidelines for the six-minute walk test. Am J Respir Crit Care Med. 2002;166(1):111-17. [PMID:12091180]

http://dx.doi.org/10.1164/ajrccm.166.1.at1102

23. Gibbons WJ, Fruchter N, Sloan S, Levy RD. Reference values for a multiple repetition 6-minute walk test in healthy adults older than 20 years. J Cardiopulm Rehabil. 2001;21(2):87-93. [PMID:11314289] http://dx.doi.org/10.1097/00008483-200103000-00005

24. Chetta A, Zanini A, Pisi G, Aiello M, Tzani P, Neri M, Olivieri D. Reference values for the 6-min walk test in healthy subjects 20-50 years old. Respir Med. 2006;100(9): 1573-78. [PMID:16466676] http://dx.doi.org/10.1016/j.rmed.2006.01.001

25. Pohl PS, Duncan PW, Perera S, Liu W, Lai SM, Studenski $\mathrm{S}$, Long J. Influence of stroke-related impairments on performance in 6-minute walk test. J Rehabil Res Dev. 2002;39(4):439-44. [PMID:17638141]

26. Mossberg KA, Fortini E. Responsiveness and validity of the six-minute walk test in individuals with traumatic brain injury. Phys Ther. 2012;92(5):726-33. [PMID:22282772] http://dx.doi.org/10.2522/ptj.20110157

27. King MB, Judge JO, Whipple R, Wolfson L. Reliability and responsiveness of two physical performance measures examined in the context of a functional training intervention. Phys Ther. 2000;80(1):8-16. [PMID:10623956]

28. Gailey R. Predictive outcome measures versus functional outcome measures in the lower limb amputee. J Prosthet Orthot. 2006;18(1s):51-60. http://dx.doi.org/10.1097/00008526-200601001-00006

29. Hansen AH, Childress DS, Knox EH. Prosthetic foot rollover shapes with implications for alignment of trans-tibial prostheses. Prosthet Orthot Int. 2000;24(3):205-15. 


\section{[PMID:11195355]}

http://dx.doi.org/10.1080/03093640008726549

30. Schneider K, Hart T, Zernicke RF, Setoguchi Y, Oppenheim W. Dynamics of below-knee child amputee gait: SACH foot versus Flex foot. J Biomech. 1993;26(10): 1191-1204. [PMID:8253824] http://dx.doi.org/10.1016/0021-9290(93)90067-O

31. Torburn L, Perry J, Ayyappa E, Shanfield SL. Below-knee amputee gait with dynamic elastic response prosthetic feet: a pilot study. J Rehabil Res Dev. 1990;27(4):369-84. [PMID:2089148] http://dx.doi.org/10.1682/JRRD.1990.10.0369

32. Reiber GE, McFarland LV, Hubbard S, Maynard C, Blough DK, Gambel JM, Smith DG. Servicemembers and veterans with major traumatic limb loss from Vietnam war and OIF/ OEF conflicts: survey methods, participants, and summary findings. J Rehabil Res Dev. 2010;47(4):275-97. [PMID:20803399] http://dx.doi.org/10.1682/JRRD.2010.01.0009

33. Stinner DJ, Burns TC, Kirk KL, Ficke JR. Return to duty rate of amputee soldiers in the current conflicts in Afghanistan and Iraq. J Trauma. 2010;68(6):1476-79.

[PMID:20068483] http://dx.doi.org/10.1097/TA.0b013e3181bb9a6c

34. Sciurba F, Criner GJ, Lee SM, Mohsenifar Z, Shade D, Slivka W, Wise RA; National Emphysema Treatment Trial Research Group. Six-minute walk distance in chronic obstructive pulmonary disease: reproducibility and effect of walking course layout and length. Am J Respir Crit Care Med. 2003;167(11):1522-27. [PMID:12615634] http://dx.doi.org/10.1164/rccm.200203-1660C
35. Enright PL. The six-minute walk test. Respir Care. 2003; 48(8):783-85. [PMID:12890299]

36. Gailey RS, Gaunaurd I, Agrawal V, Finnieston A, O’Toole C, Tolchin R. Application of self-report and performancebased outcome measures to determine functional differences between four categories of prosthetic feet. J Rehabil Res Dev. 2012;49(4):597-612. [PMID:22773262] http://dx.doi.org/10.1682/JRRD.2011.04.0077

Submitted for publication May 30, 2012. Accepted in revised form December 4, 2012.

This article and any supplementary material should be cited as follows:

Linberg AA, Roach KE, Campbell SM, Stoneman PD, Gaunaurd IA, Raya MA, Gomez-Orozco C, Gailey RS. Comparison of 6-minute walk test performance between male Active Duty soldiers and servicemembers with and without traumatic lower-limb loss. J Rehabil Res Dev. 2013;50(7):931-40.

http://dx.doi.org/10.1682/JRRD.2012.05.0098

ResearcherID/ORCID: Robert S. Gailey, PhD, PT: I3458-2013; Ignacio A. Gaunaurd, PhD, MSPT: I-34902013

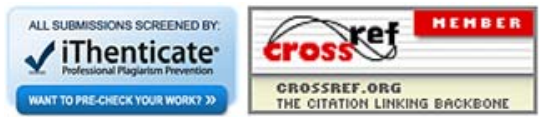


